\title{
Erratum to: Courses of helping alliance in the treatment of people with severe mental illness in Europe: a latent class analytic approach
}

\author{
Sabine Loos • Katrin Arnold • Mike Slade • Harriet Jordan • Valeria Del Vecchio • \\ Gaia Sampogna • Ágnes Süveges • Marietta Nagy • Malene Krogsgaard Bording • \\ Helle Østermark Sørensen • Wulf Rössler • Wolfram Kawohl • Bernd Puschner • \\ The CEDAR study group
}

Published online: 11 February 2015

(c) Springer-Verlag Berlin Heidelberg 2015

\section{Erratum to: Soc Psychiatry Psychiatr Epidemiol \\ DOI 10.1007/s00127-014-0963-4}

In the original publication of the article, the given and family names of the co-author, Valeria Del Vecchio have been published incorrectly both in the author list and affiliation. The corrected author list is given here.

The online version of the original article can be found under doi:10.1007/s00127-014-0963-4.

\section{S. Loos $(\bowtie)$}

Department of Child and Adolescent Psychiatry and

Psychotherapy, University Hospital Ulm, Ulm, Germany

e-mail: sabine.loos@uniklinik-ulm.de

K. Arnold · B. Puschner

Section Process Outcome Research, Department of Psychiatry II,

Ulm University, Günzburg, Germany

M. Slade $\cdot$ H. Jordan

Section for Recovery, Institute of Psychiatry, King's College

London, London, UK

V. Del Vecchio · G. Sampogna

Department of Psychiatry, University of Naples SUN, Naples, Italy
Á. Süveges · M. Nagy

Department of Psychiatry, Medical and Health Science Center, University of Debrecen, Debrecen, Hungary

M. Krogsgaard Bording · H. Østermark Sørensen

Unit for Psychiatric Research, Aalborg Psychiatric Hospital,

Aalborg University Hospital, Aalborg, Denmark

W. Rössler

Department of General and Social Psychiatry, University of Zurich, Zurich, Switzerland

W. Kawohl

Department of Psychiatry, Psychotherapy and Psychosomatics, Centre for Social Psychiatry, Psychiatric Hospital, University of Zurich, Zurich, Switzerland 